EESTI NSV TEADUSTE AKADEEMIA TOIMETISED. 27. KÖIDE

KEEMIA. 1978, NR. 1

ИЗВЕСТИЯ АКАДЕМИИ НАУК ЭСТОНСКОИ ССР. ТОМ 27 Химия. 1978, № 1

Ю. КАУП, Марина ГРИНЧАК, О. ЭИЗЕН

удк $547.538 .241 .541 . ! 3$

\title{
ПРЕВРАЩЕНИЕ ФЕНИЛАЦЕТИЛЕНА В ВОДОРОДНОИ ПЛАЗМЕ ВЧ-ТЛЕЮЩЕГО РАЗРЯДА
}

I. KAUP, Marina GRINCHAK, O. EISEN. FENOOLATSETOLEENI MUUNDUMISEST VESINIKU HUUMLAHENDUSPLASMAS

J. KAUP, Marina GRINCHAK, O. EISEN. ON THE DECOMPOSITION OF PHENYLACETYLENE IN HYDROGEN PLASMA OF GLOW DISCHARGE

Установлено, что молекулярный водород активируется в электрических разрядах и может непосредственно взаимодействовать с активированными молекулами других органических веществ [1, 2].

В $\left.{ }^{3}\right]$ нами показано, что при взаимодействии активированного ВЧтлеющим разрядом ацетилена с активированным водородом (водород в состоянии плазмы) имеет место присоединение водорода к тройной связи, и образуются как этилен, так и этан, выход которых составляет до 2,7 и $27 \%$ соответственно от взятого ацетилена.

В настоящей работе изучено превращение фенилацетилена в водородной плазме ВЧ-тлеющего разряда в целях выяснения возможности присоединения водорода к тройной связи фенилацетилена.

Исследование превращения фенилацетилена в водородной плазме проводили в аппаратуре проточного типа, аналогичной описанной в $[3,4]$. Смесь фенилацетилена и водорода (молярное соотношение $1: 5$ ) подвергали действию разряда, мощность которого варьировали от 120 до 200 мА по анодному току ВЧ-генератора $(13,56 \mathrm{Mәц})$. Объем разрядной зоны составлял 10 мл, время контакта $\sim 0,05$ сек. Реактор охлаждали снаружи воздухом, нагнетаемым вентилятором. Все опыты проводили при давлении 3 мм рт. ст.

Продукты реакции анализировали с помощью газового хроматографа «Вырухром». В качестве стационарных фаз для анализа жидких продуктов реакции использовали полиэтиленгликоль 6000 и динонилфталат. Компоненты реакционной смеси идентифицировали, применяя индивндуальные углеводороды. Газовые продукты анализировали на полисорбе-1.

Известно [5], что область благоприятных условий для проведения бимолекулярных реакций двух различных компонентов в электрических разрядах исключительно узка, так как для инициирования таких процессов следует активировать оба компонента (в наших условиях фенилацетилен и водород) до степени, необходимой для реакции между ними. В противном случае, реагирует лишь одно из исходных соединений, образуя ди- нли полимеры.

4 ENSV TA Toimetised. K 11978 


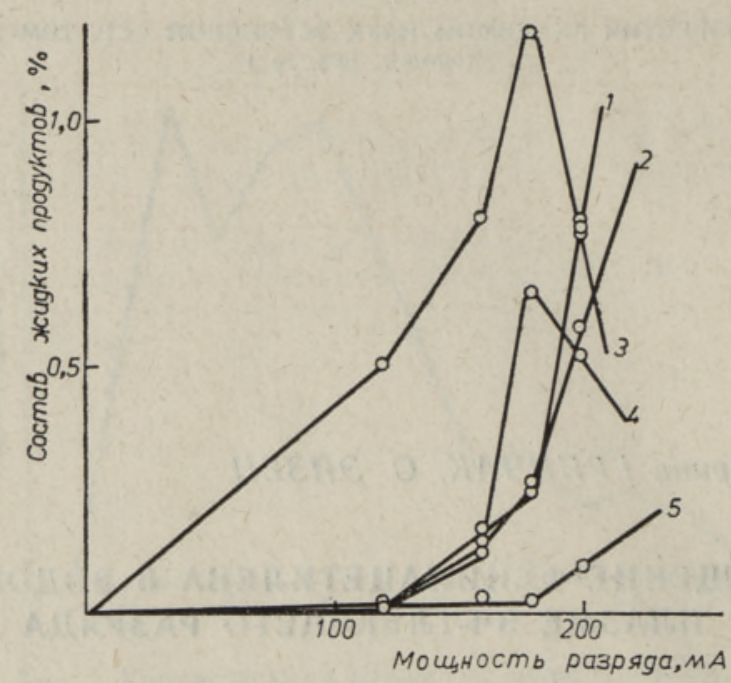

Зависимость содержания бензола (1), толуола (2), стирола (3), этилбензола (4) и ксилолов (5) в продуктах превращения фенилацетилена от мощности разряда.

Как следует из наших опытов, превращение фенилацетилена в водородной плазме ВЧ-тлеющего разряда (схема) протекает в нескольких направлениях и включает процессы распада, отщепления, замещения, а также полимеризацию. Аналогичные явления наблюдались и в реакциях бензола и толуола с $\mathrm{CH}_{3} \mathrm{X}(\mathrm{X}=\mathrm{Cl}, \mathrm{Br})\left[{ }^{6}\right]$, толуола с $\mathrm{NH}_{3}\left[{ }^{7}\right]$ и $\mathrm{CH}_{3} \mathrm{CN}\left[{ }^{8}\right]$.

\section{Схема превращения фенилацетилена в водородной} плазме ВЧ-тлеющего разряда

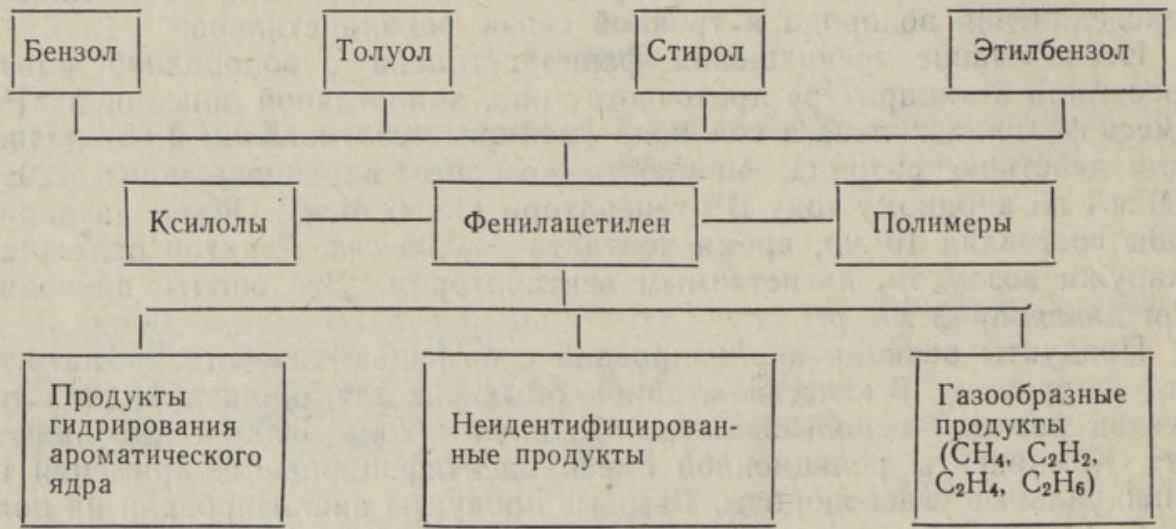

\&.

Нами показано [3], что условия реакции (мощность разряда) оказывают существенное влияние на ход присоединения водорода к тройной связи ацетилена. В случае реакции превращения фенилацетилена в водородной плазме мощность разряда в основном влияет на степень превращения фенилацетилена и на образование полимеров (таблица).

Следует отметить, что образуются и продукты гидрирования арома- 
Зависимость состава продуктов превращения фенилацетнлена в водородной плазме от мощности ВЧ-тлеющего разряда

\begin{tabular}{|c|c|c|c|c|}
\hline \multirow{2}{*}{ Состав, \% } & \multicolumn{4}{|c|}{ Мощность разряда по анодному току, $м A$} \\
\hline & 120 & 160 & 180 & 200 \\
\hline Бензол & 0,007 & 0,165 & 0,240 & 0,793 \\
\hline Толуол & 0,013 & 0,143 & 0,257 & 0,579 \\
\hline Этилбензол & 0,100 & 0,126 & 0,649 & 0,522 \\
\hline Ксилолы & 0,013 & 0,049 & 0,027 & 0,089 \\
\hline Стирол & 0,637 & 0,780 & 1,271 & 0,778 \\
\hline Фенилацетилен & 65,830 & 53,011 & 40,534 & 23,227 \\
\hline Метан & 0,100 & 0,900 & 1,000 & 1,000 \\
\hline Этан & 0,500 & 0,800 & 0,500 & 0,500 \\
\hline Этилен & 0,100 & 2,400 & 3,300 & 4,000 \\
\hline Ацетилен & 0,500 & 2,600 & 3,600 & 4,500 \\
\hline $\begin{array}{l}\text { Неидентифицированные жидкие } \\
\text { продукты }\end{array}$ & & & & \\
\hline Твердые полимеры & $\begin{array}{r}0,400 \\
31,800\end{array}$ & $\begin{array}{r}0,626 \\
38,400\end{array}$ & $\begin{array}{r}0,615 \\
48,000\end{array}$ & $\begin{array}{r}1,712 \\
62,300\end{array}$ \\
\hline
\end{tabular}

тической части фенилацетилена - производные циклогексана, циклогексена и циклогексадиена.

На основе наших данных можно сделать вывод о том, что превращение фенилацетилена в водородной плазме ВЧ-тлеющего разряда в направлении фенилацетилен $\stackrel{\mathrm{H}_{2}}{\longrightarrow}$ стирол $\stackrel{\mathrm{H}_{2}}{\longrightarrow}$ этилбензол имеет место в незначительной степени. Оптимальной мощностью разряда с точки зрения этой реакции является 180 мA, причем выход стирола и этилбензола составляет соответственно 1,28 и $0,65 \%$. (рисунок).

Основным направлением превращения фенилацетилена в водородной плазме ВЧ-тлеющего разряда является полимеризация. Образующиеся при этом полимеры представляют собой твердые порошкообразные вещества, нерастворяющиеся в обычных растворителях.

\section{Л ИТ Е РАТ У РА}

1. Бе бе ш ко Г. И., Е р е м и н Е. Н., Ж. физ. химии, 48,95 (1974).

2. Бе б ешко Г. И., Е р ем и н Е. Н., Ж. физ. химин, 48, 611 (1974).

3. К а уп Ю. Ю., Эй з ен О. Г., Химия высоких энергий, 11, 100 (1977).

4. К а у п Ю., Эй з е н О.. Изв. АНН ЭССР, Хим. Геол., 26, 18 (1977).

5. S u h r, H., Angew. Chem., 84, 876 (1972).

6. Kikkawa, S., Nomura, M., Tanida, M., Techn. Repts of the Osaka University, 25, 233 (1975)

7. Matsuda, S., Kikkawa, S., Oka, S., T an a ka, Y., J. Chem. Soc. Japan Ind. Chem. Snct., 71, 1499 (1968).

8. Kikkawa, S., Nomura, M., Tanaka, Y., Doi, H., Sumi, H., J. Chem. Soc. Japan, Pure Chem. Snct., 93, 1463 (1972).

Ннститут химии

Академии наук Эстонской ССР
Поступила в редакцию 1/III 1977 